\title{
CONCEPCIÓN DEL HECHO NORMATIVO EN LA DECLAMACIÓN DE JOSÉ DE VARGAS PONCE
}

CARLOS MORIYÓN MOJICA

Universidad de Valladolid

La preocupación por el estado de corrupción de la lengua castellana lleva a José de Vargas Ponce hasta su Declamación contra los abusos introducidos en el castellano ${ }^{1}$. La obra, dividida en dos partes, incluye, para el momento de su publicación, una tercera: un diálogo entre el autor, D. Justo y D. Severo, en el que Vargas explica el plan adoptado y las razones que, a su juicio, motivan el que su trabajo no haya sido premiado por la Academia Española, basándose, para ello, en la crítica de los intereses que para entonces guiaban a la institución española.

Nuestro objetivo, directamente relacionado con la concepción de la normatividad lingüística, nos obliga a dejar de lado aquí el análisis del conjunto de situaciones suscitadas por la decisión de Vargas Ponce de publicar su obra a pesar de haber sido rechazada por la Academia. Nos interesan, no obstante, las razones «aparentemente» esgrimidas para justificar el fallo ${ }^{2}$, pues ellas ponen

1 Vid. Jose dE VARgas PONCE (1793), Declamación contra los abusos introducidos en el Castellano. Presentada y no premiada en la Academia Española, año de 1791. Síguela una disertacion sobre la Lengua Castellana, y la antecede un diálogo que explica el designio de la obra. (Al pie, luego de un escudo; Madrid, MDCCXCIII. En la imprenta de la viuda de Ibarra. Con las licencias necesarias). La obra aparece identificada aquí como (DA).

2 Hablamos de razones *aparentes», porque nos atenemos a las aludidas por Vargas Ponce en su Declamación. Éstas son, además, las que destaca el licenciado Pablo Ipnocausto, seudónimo 
de manifiesto el hecho de que la Declamación contra los abusos resultaba «un continuo plagio de las obras de Aldrete y Mayans» (DA:XXIII).

Sin ánimos de profundizar en el asunto, tenemos que decir que es cierto que la Declamación carece de originalidad ${ }^{3}$ y que, en verdad, se traduce en una recopilación de datos contenidos en las obras a las que se le acusa de plagiar. A pesar de ello, y sin que esto signifique una disculpa, no es posible dejar de reconocer que el mal de Vargas Ponce es el mismo del que adolecen innúmeras obras gramaticales de la tradición gramatical española, que se limitan a seguir incansablemente - y a veces demasiado de cerca - a grandes obras como las de Nebrija o la propia Academia.

Por otra parte, el propio Vargas Ponce reconoce en el diálogo que antecede a la obra que se valió de esos autores y, además, de «el Diálogo de las lenguas, los de Duarte Nuñez, los de Velazquez y Sarmiento, las Obras de la Academia, todos los Diccionarios y Poeticas Castellanas, buena parte de sus Retóricas y Gramáticas y comentos de los poetas, y los mejores y peores libros nuestros prosaicos y metricos desde 1200" (DA:XXIV). Es claro que el autor alude aquí a sus múltiples fuentes, que, por otra parte, pueden ser encontradas en cualquiera de las páginas de la Declamación, y no a lo que realmente quiere darse a entender en las críticas a su obra. En cualquier caso, resulta cierto que las referencias a todos esos autores son constantes en la Declamación.

\section{LA DOCTA AUTORIDAD}

Los comentarios hechos hasta aquí no pretenden insistir en el problema de la existencia o no de plagio, sino poner de relieve el hecho de que todas las noticias ofrecidas por Vargas Ponce se ven siempre refrendadas por el aval que

de Juan Pablo Forner, en un folleto publicado contra la Declamación. Vid. JUAN PABLo Forner (1795), La Corneja sin Plumas, Fragmento Póstumo del Licenciado Pablo Ipnocausto, Puerto de Santa María, Por Don Luis de Luque y Leyva, Año de MDCCXCV.

3 A pesar de ello, Vargas reclama la knovedad», «utilidad» y «provecho» de su obra, que «con más extensión que en los Opúsculos que hasta ahora ha dado la Academia, 6 en los de Argote de Molina; con mas individualidad, conocimiento y substancia que el Discurso de Feijoo, paralelo de las Lenguas; con mas dignidad que el padre Terreros, mas método que Mayans y en mucho menos pepel que Aldrete presenta los orígenes y vicisitudes de nuestro idioma Castellano, y clama por la reforma de sus vicios». Cfr. José de Vargas PONCE (DA:XXIII). 
ofrece «la autoridad», pues no con otra intención son aludidos en la Declamación.

El valor de la autoridad no admite discusión en la obra de Vargas Ponce. El prestigio que ofrece a una regla, un principio o una observación cualquiera el haber sido recogidos con anterioridad por algún autor renombrado es constantemente resaltado en la Declamación. Tales autores son reconocidos, además, como «autoridad», y su postura en relación con el aspecto tratado, como inmutable «doctrina» ${ }^{4}$.

La importancia de la autoridad en el establecimiento y la generalización de una norma determinada queda expresada con claridad en la Declamación, en la que se da cumplida cuenta de dos «usos» lingüísticos bien diferenciados, el «vulgar» o general, propio de los «imperitos», y el culto, propio de los «doctos» $\mathrm{y}$ «eruditos» $\mathrm{y}$ único uso capaz de servir de norma.

Para Vargas Ponce, el término «uso» puede resultar ambiguo, pues por él puede entenderse «uso vulgar». De ahí, el que el autor se apresure a aclarar que, gramaticalmente, la expresión «uso de la lengua» sólo puede ser interpretado como «la congregación de los Eruditos», de la misma manera que por «uso para las costumbres» sólo se entiende «la congregacion de los hombres de bien» (DA:XVII).

La postura de Vargas Ponce pretende destacar el peligro que supondría para la lengua «dar por precepto» el uso vulgar de los «imperitos», a lo que Vargas niega la posibilidad de ser considerado como «uso». Por eso advierte que «Si lo que muchos hacen mereciese tal nombre, dar por precepto el uso, sería peligrosísimo, no solo en la elocucion, sino tambien en la conducta humana (...) así en el habla no se ha de recibir por regla suya en lo que muchos viciosamente incurren. Porque omitiendo de que manera hablan habitualmente los imperitos, sabemos de quan bárbaro modo de ordinario exclaman los teatros y sus concurrentes» (DA:XVII).

El «uso», sostiene el autor de la Declamación, no puede ser más que «docto uso» y sólo éste puede ser mirado como «norma» de la lengua. Vargas Ponce corrobora su opinión en este sentido cuando, apoyándose de nuevo en el principio de autoridad, da cuenta de que así lo ha dejado ver, por ejemplo, «uno de los padres del Frances correcto» al afirmar que «el mal uso se forma del mayor numero de personas», pero que el «bueno», «no lo compone la pluralidad, sino los votos escogidos; y estos son los rectamente dichos NORMA de las Lenguas» (DA:XVIII).

4 «... y es doctrina explicada para nosotros y nuestra Lengua por muchos doctos como Fernando Herrera, Mayans, Terreros, Larramendi, Azara, Fernandez y Garces, ...». Cfr. JoSÉ DE VAR. GAS PONCE (DA:XIII). 
Ese «uso bueno» — «recto y regulador en materia de idiomas»- es sustancialmente distinto de ese otro uso «malo» o impropio «contra el qual puede qualquiera con razon sublevarse» (DA:XVIII). Está claro, entonces, que ambos no pueden ser considerados «uso». La denominación sólo resulta aplicable al "recto uso", interpretable como norma, mientras que con el otro "no habrá lugar la prescripcion» (DA:XVIII).

El uso «general» es, definitivamente, un uso «vulgar», «corrompido», lo que no tiene nada de extraño cuando se piensa que ese empleo que de la lengua hace «la imperita muchedumbre, que jamás estudió ni leyó siquiera un Autor clásico nacional» (DA:XVIII). Por eso el verdadero «uso», el «docto», no puede buscarse en el empleo «vulgar» del hablante común. Pero, tampoco, «en un tocador 6 en un corro de Eruditos á la violeta» 5 . Hay que buscarlo, entonces, "por los renglones de un Maestro León, o de un Fernando Herrera». Sólo lo que «aquellos consolidadores del castellano declararon puro y corriente» puede ser mirado como «uso", pues "corriente y puro quiere la razon y el juicio que lo esté todavía», gracias al «consensum eruditorum». Éste, y no otro, es, además, «el verdadero uso que seguia Julio Cesar en su idioma, enmendando abusos introducidos» (DA:XVIII).

Las observaciones anteriores no permiten poner en duda el sentido que el término "uso» adquiere en la obra, ni el hecho de que sea precisamente el uso culto el que se busca elevar a la categoría de norma. Y si el «docto uso» constituye la norma, no pueden ser otros que los «eruditos» los depositarios de la autoridad normativa. Los gramáticos ${ }^{6}$, poetas ${ }^{7}$ y escritores ${ }^{8}$ - los doctos, en su-

${ }^{5}$ En clara alusión a la composición de José Vázquez, pseudónimo de José CaDalso, «Los Eruditos a la violeta» (1772).

${ }^{6}$ Entre los numerosísimos ejemplos que podríamos traer aquí, extraemos el que hace referencia a Nebrija: «Vino al fin Antonio de Lebrixa, y hallando el habla Castellana poderosa en términos y apacible, clara en la frase, docil y manejable, de nobleza y energía, sujetóla á reglas, y alzó pendón para acaudillar preceptos». Cfr. JOSE DE VARGAS PONCE (DA:20).

7 Las referencias son innumerables, pero baste con éstas: «... pues subiendo nuestras composiciones á una grandeza y armonía desconocidas, se lucieron tanto Boscán y Mendoza, Gutierre de Cetina y Luis de Haro; y el dulce Poeta de la sensibilidad y del corazon, el afectuoso y tierno Garcilaso descolló sobre todos, mostrándose como un insigne dechado de su género"; "Por la gravedad y nobleza de la Épica Virues y Acuña; por el entusiasmo y lo enfático de la alta Lira el sublime Leon y sus Odas, los inflamados y juiciosos Argensolas, y sus canciones y sonetos; en el sencillo y afectuoso Bucólico Figueroa y Morales; en el delicado y ligero Anacreóntico, el fácil Silvestre, y el natural y exquisito Villegas; en el picante y caústico de la sátira Naharro y Castillejo; en la agudeza y sales del epigrama Alcazar y Salas Barbadillo; en el corriente y puro de la comedia Rueda y Guillen de Castro, y Espinel, y Esquilache, y Cangas, y Mosquera de Figueroa, y Barahona, y Artieda, y Ro$x a s, y$ tantos mas en varios de estos géneros». Cfr. José DE VARGAS PONCE (DA:21-22 y 24-25).

8 A modo de ejemplo, reproducimos estas referencias: «Aquel Corifeo del habla Castellana, el esclarecido y remontado Fr. Luis de León la enriqueció y dotó de estas ultimas prendas (se refie- 
ma- son los únicos facultados para regir los destinos de la lengua. Y entre éstos, las más «espesas autoridades» están representadas, como es lógico, por “todos los diligentes Escritores de nuestro Siglo de Oro» (DA:XX).

\section{La Razón, Privilegio de los Doctos}

Todos lo referido hasta aquí puede hacer pensar que si el «uso docto» constituye la norma, la autoridad ha de ser, por fuerza, el primer fundamento de la Declamación. No obstante, ello no es así, al menos no teóricamente. Tal prerrogativa le cabe únicamente a la razón, considerada «primera regla del idioma», claro que sólo por su íntima relación con la docta autoridad, de la que parece resultar privilegio.

La relación de subordinación que la autoridad guarda con respecto a la razón queda expresada con claridad meridiana por Vargas Ponce, quien muestra a sus críticos la firmeza de su convicción con estas palabras: «Por eso yo, mal que le pese á qualquiera, seguiré siempre las venerables huellas que aconsejaba Lope; pues sé (y escúdeme de nuevo Quintiliano) que la autoridad despues de la razon es la segunda regla del idioma y que en nada peca quien usa continuo de los vocablos que emplearon los sumos Escritores, cuyo juicio vale por razon de la Eloquencia, y á cuya ilustre sombra hasta el error es honesto y disculpable» (DA:XX).

Las palabras de autor son terminantes. La razón es la primera regla del idioma, y subordinada a ésta, se encuentra la autoridad. A pesar de ello, el aserto de Vargas no es más que una sutileza linguiística. No hay más que una razón, la docta, por lo que, en la práctica, se hace difícil establecer con claridad la primacía de una sobre la otra. Los doctos, los que tienen autoridad, no actúan sino conforme a razón; y ésta, en lo tocante a la lengua, no es dada a nadie más. La

re a la "sublimidad" y la "cadencia") á costa de sudores, y de limar y castigar sus preciosos y admirables escritos, ayudándole en tan ilustre empresa el no tan conocido Fernando de Herrera, aunque tan digno de serlo»; «Nuevo Linage de Crónicas se escribieron con suma elegancia por Yepes, Sigüenza y Cornejo; los discursos y obras morales por el afluentísimo Guevara, y el claro y jovial Villalobos, y el delicado Valles; las obras didácticas por Herrera y Acosta. Brilló en las de imaginacion y de ingenio la feliz abundancia del facundo y vehemente Aleman, la inimitable propiedad y gracia, y aquel castizo y acendrado lenguaje del mas famoso de sus libros humanos». Cfr. JoSÉ DE VARGAS PONCE (DA:22 y 24). 
razón parece, pues, una característica del erudito, inseparable de su actuación y no algo a lo que ésta se subordina.

La postura de Vargas Ponce en este sentido se funda en una actitud absolutamente común en estos siglos. En la tradición gramatical española, el uso se hace norma. Y como natural consecuencia de las enseñanzas de Quintiliano. éste aparece unas veces asociada a la autoridad, otras al uso común y otras a la razón, los tres fundamentos que el célebre gramático lega a la gramática española - «Est etiam sua loquentibus observatio, sua scribentibus. Sermo constat ratione, uetutate, auctoritate, consuetudine» ${ }^{9}$ - Pero los tres fundamentos se hacen uno en las obras de nuestra tradición gramatical porque, para muchos de nuestros gramáticos y tratadistas, autoridad y razón no son más que otros usos.

Como había dejado ver el primer Diccionario académico, «autoridad» es «exceléncia, representación, estimación adquirida, 6 por la rectitúd de la vida y eminencia de la virtud, $\partial$ por lo respetable de la nobleza y de la edad, 6 por lo grande de la sabiduría, poderío, honor y otros títulos que hacen à uno digno de singular atención ${ }^{10} »$, pero también «se toma por el texto, ò palabras que se citan de algunos libros, $\partial$ sugétos que hacen y deben hacer opinión ${ }^{11}$, con lo que autoridad es, igualmente, sinónimo del uso recogido en esos textos ${ }^{12}$, un uso que «hace y debe hacer opinión». Y tanta, que muchos se atreverán, incluso, a asegurar que «solo el Facultativo (como Perito) puede escribir como quisiére ${ }^{12}$ ». El resto, «el mero, y solo Castelláno», debe contentarse con seguir el empleo que de la lengua quiera imponer el docto. Su uso no debe ser tomado en cuenta para nada, «ni para èl se debe escribir ${ }^{13}$ ».

La «razón», por su parte, se define en estos siglos como «el acto del entendimiento o discurso», como «la potencia intelectiva, en quanto discurre y raciocina ${ }^{14} \gg$; pero ésta se asocia, como en Vargas Ponce y muchos otros, con los hombres doctos, pues sistemáticamente se niega a quienes no son capaces de poner «orden y méthodo» a las cuestiones de la lengua. Con ello, sólo el docto uso de los hombres cultos se ajusta a razón, que pasa así a relacionarse sólo

9 Cfr., M. F. Quintiliano, Instituciones Oratorias, Texte étabile et traduit par Jean Cousin, París, Les Belles Lettres, 1975, I, p. 6.

10 Cfr. Real Academia Española, Diccionario de Autoridades, Madrid, Gredos, $3^{2}$ reimpr., 1976, p. 490.

11 Ibid.

12 Cfr. Juan de lama (1786), La perla de las dos lenguas, Alma, y Norte seguro de su pronunciacion; el Acento de la Latína, y Castellána, con lo mas comun y esencial de la Ortografia moderna; para saberla hablar, escribir, lèr, pronunciar y acentuar con toda propiedad, y elegancia, todo genero de personas domésticas y estrañas. Sacado de las Obras de Don JUAN DE LAMA, p. 55.

13 Ibid.

14 Cfr. Real academia Española, Op. cit., p. 500. 
con la costumbre de emplear este uso, pues, como deja ver Bordázar ${ }^{15}$, «la razón se funda, en que uso no es otra cosa sino repetidos actos convenientes a la razon, i apartandose de esta, son abuso, o contra uso ${ }^{16}$ ", lo que hará que posteriormente algunos como Brunot, den cuenta de que muchos de los gramáticos «supuestamente» racionalistas sólo convierten a la razón en esclava de la autoridad $^{17}$ al ponerla al servicio de un uso concreto.

\section{Un Nuevo ENEMigo: El Galicismo}

Desde su nacimiento, el romance español había tenido que enfrentar la lucha con el latín. Para imponerse como lengua general primero; para descollar en ciertos campos culturales después. Los enfrentamientos, cargados de violencia en algunos casos, habían resultado poco a poco favorables para el español, que, desde una posición de evidente desventaja, había ido ganando posiciones y convirtiéndose, en opinión de la mayoría docta, en lengua cultural con la misma pureza y perfección que la lengua sabia.

La lucha que ha de enfrentar el romance español sigue siendo una constante en el siglo XVIII. Las circunstancias y los enemigos son, empero, distintos. El español se ha ganado, incluso a ojos de importantes hombres de artes y ciencias, un prestigioso lugar como lengua apta para la cultura. La forma que la lengua presenta es, no obstante, absoluta y constantemente cambiante. Y ello, principalmente, porque sigue enfrentando constantes ataques. La barbarie barroquizante para algunos, los neologismos para otros, pero sobre todo los galicismos - piensa Vargas Ponce- son algunos de sus nuevos enemigos. Por eso se justifica plenamente la Declamación contra los abusos introducidos en el castellano.

La influencia intelectual que Francia ejerce en todo el territorio continental se deja sentir en España y en el español. Las denuncias sobre los estragos que el galicismo hace en la lengua de España son frecuentes a lo largo de todo el siglo XVIII. Aquella España dividida en dos bandos de la que habla Piquer

15 Sobre la postura normativa del autor, vid. CARLOS MORIYón MoJiCA, «Normatividad y estandarización en la obra de Antonio Bordázar de Artazú», Letras de Deusto, 1993 (en prensa).

$16 \mathrm{Cfr}$. ANTONIO BORDAZAR, Ortografía española, fijamente ajustada a la naturaleza invariable de cada una de las Letras (1728), Valencia, Imprenta del autor, 1730, p. 93.

17 Vid. F. BRUNot (1966), Histoire de la langue fraçaise des origines á nous jours, París, Vol. IV, pp. 53-58. 
parece haber concentrado uno de ellos en la Corte española, que, embelesada, no tiene ojos más que para Francia. La conversación cortesana, igual que toda la Corte, ha sido alcanzada por la moda francesa. Las quejas en este sentido se multiplican sin cesar. El padre Isla, por ejemplo, es uno de los autores que advertirá que el habla de los cortesanos, representada en el Fray Gerundio por don Carlos, «se había pegado fuertemente al aire de la gran moda». A la queja de Isla pueden sumarse, entre otras muchas, la de Cadalso, quien, en una de sus Cartas Marruecas (1789), evidencia el fervor que España siente por Francia $^{18}$, la del padre Sarmiento, quien, en su Demostración crítico-apologética, denuncia «la introducción de algunas voces extrañas» y, como no, la de Vargas Ponce, uno de los más fuertes opositores con los que se encontrará el galicismo.

Para Vargas Ponce, la lengua de Francia - una lengua «imperfecta de sus hechuras, un dialecto mal formado, mezquino y pobre, monótono y seco y duro, sin fluidez, sin copia, sin variedad»— «se entrometió á pervertir» el romance Castellano (DA:37). La «alteracion», reconoce el autor, ha estado determinada por el «íntimo comercio de hombres y libros», y «empezo por los vocablos, despojándose los propios, expresivos y gratos, las oportunas onomatopeyas por los de obscuro origen y de aquiende de los Pirineos insignificantes», lo que influyó para que «conocimientos antiguos que de nosotros pasaron á la Europa entera, fueron ya pronunciados á la Francesa, y así reconocidos por Españoles». La situación, crítica para Vargas Ponce, lo lleva a afirmar que el francés «fué la primera plaga que á la descubierta acometió y afligió al Castellano» (DA:39), una plaga contra la que se lucha denodadamente desde la Declamación.

\section{LA ESTANDARIZACIÓN, REQUISITO ÚLTIMO DE LA NORMA}

Si Vargas Ponce se muestra tan insistente sobre las características y los fundamentos de la norma ello se debe, como hemos visto, al estado de corrupción que aprecia en la lengua. $Y$ es que, como tantas veces, el problema reside en que las normas adecuadas, fijadas en los textos por los grandes escritores

18 La carta de la hermana de Nuño que Cadalso incluye en la Carta XXXV es, al tiempo que una logradísima pieza satírica, una tremenda denuncia de lo que le está ocurriendo al español y a la sociedad de entonces, sometidos al fuerte influjo de la moda afrancesada. 
clásicos, no han logrado la generalización. El vulgo $-\mathrm{y}$, lo que es peor, también algún docto-, «abandona semejante guia» y hace uso de su lengua, únicamente "guiado de su antojo», lo que hace de ella un cuerpo cada vez más corrompido.

Las causas de la corrupción de la lengua son cuidadosamente analizadas en la Declamación. El abandono al que los escritores han relegado los buenos libros, el desdén con el que se miran las lenguas sabias, la desmesurada incorporación de galicismos, las cada vez más numerosas malas traducciones, el escaso cultivo de la poesía, el aprecio por el teatro italiano en desmedro del nacional y la introducción de gustos extranjeros son los motivos que, a juicio del autor de la Declamación, están pervirtiendo la lengua castellana y consiguiendo que pierda la pureza y perfección a que había sido elevada por los grandes escritores.

Para Vargas Ponce, está claro, pues, que no se trata sólo de fijar una norma, sino de hacerla respetar, con el propósito de hacerla general. «Mas ¿que presta este reducido catálogo de Autores no leídos —se pregunta-, quando la multitud sigue un sendero tan contrario? Quando de cada momento se multiplica y ensancha la corrupcion del idioma?» (DA:46). La estandarización de una modalidad concreta —en este caso la docta- es, en consecuencia, la única salida para una lengua que, cada día más alejada de los patrones clásicos, corre el riesgo de sufrir un daño «irreparable».

La tarea es una y clara, la defensa del castellano por medio de la codificación de la lengua y su posterior estandarización. «¿Donde hallará albergue y acogida el desvalido idioma?» se pregunta Vargas Ponce. «¿A qué asilo podrá retrotraerse? ¿á qual sombra? ¿só que tutela? ¿baxo qual amparo? (...) ¿quien podrá acorrerle? ¿quien ser su valedor?». La solución, tan evidente como el problema, encuentra una única respuesta, la solicitud a una autoridad capaz de hacer respetar la norma propuesta en los textos: «Príncipe Augusto, esta grande empresa os está reservada. El lenguaje Patricio con la lista de sus méritos y el memorial de sus agravios busca vuestro patrocinio» (DA:53).

La estandarización es requisito que ya echaba en falta Nebrija cuando solicitaba la intervención de la corona en la implantación de una norma determina$\mathrm{da}^{19}$, Valdés cuando proponía una norma fundada en un uso efectivamente

19 Sobre la postura normativa del autor, véanse, entre otros, ANTONIo QULIS (19903), Estudio introductorio a su ed. de la Gramática de la Lengua Castellana de Antonio de Nebrija, Madrid, Centro de Estudios Ramón Areces, y Carlos MoriYón MOJICA, «Concepción de la normatividad en la obra gramatical de Antonio de Nebrijam, La Corónica 1992 (en prensa), y sobre la relación entre su solicitud y la única salida del planificador de entonces para conseguir la estandarización, Carlos Moriyón Mojica, «Planificación linguística ampliadora en la España de los Siglos de Oro», Anuario de Lingullstica, 1992 (en prensa). 
real $^{20}$ o García de Loaisa cuando presentaba su Memorial ante Felipe II. Pero, como ha quedado repetidamente reiterado en la praxis lingüistica, las innumerables normas ofrecidas desde las obras gramaticales no han conseguido generalizarse por el simple hecho de no haber conseguido la protección oficial. Por eso, emulando a Nebrija y a García de Loaisa, Vargas Ponce recurre de nuevo a la Corona, única autoridad capaz de hacer que se difunda la norma. De ahí, su encarecido ruego: «De vos, Señor, espera recobrar tantos derechos: renacer limpia y sin mezcla qual solia, para dominar con exclusión en la Península, y darse á conocer segunda vez en la Republica Literaria. Sea vuestro Quarto su Retrete y Templo, vuestra Familia los Ministros de su culto, y vos mismo el Sumo Sacerdote á quien esté encomendada estrechamente la honra y custodia del Númen Tutelar» (DA:53-54).

20 Sobre la concepción de la normatividad, las características de la variedad propuesta como norma y la necesidad de la estandarización, véase CARLOS MORIYón MOJICA (1988-89), «Valdés y Salinas. Dos actitudes frente a la lenguan, ELUA, 5, pp. 291-301, y CARLOS MORIYÓN MOJICA (1990), «Una respuesta de avanzada al problema de la norma linguística en el siglo XVIm, $B B M P$, L.XVI, pp. 229-255. 